\title{
A tentação orgiástica de Emma Bovary
}

\section{Emília Costa}

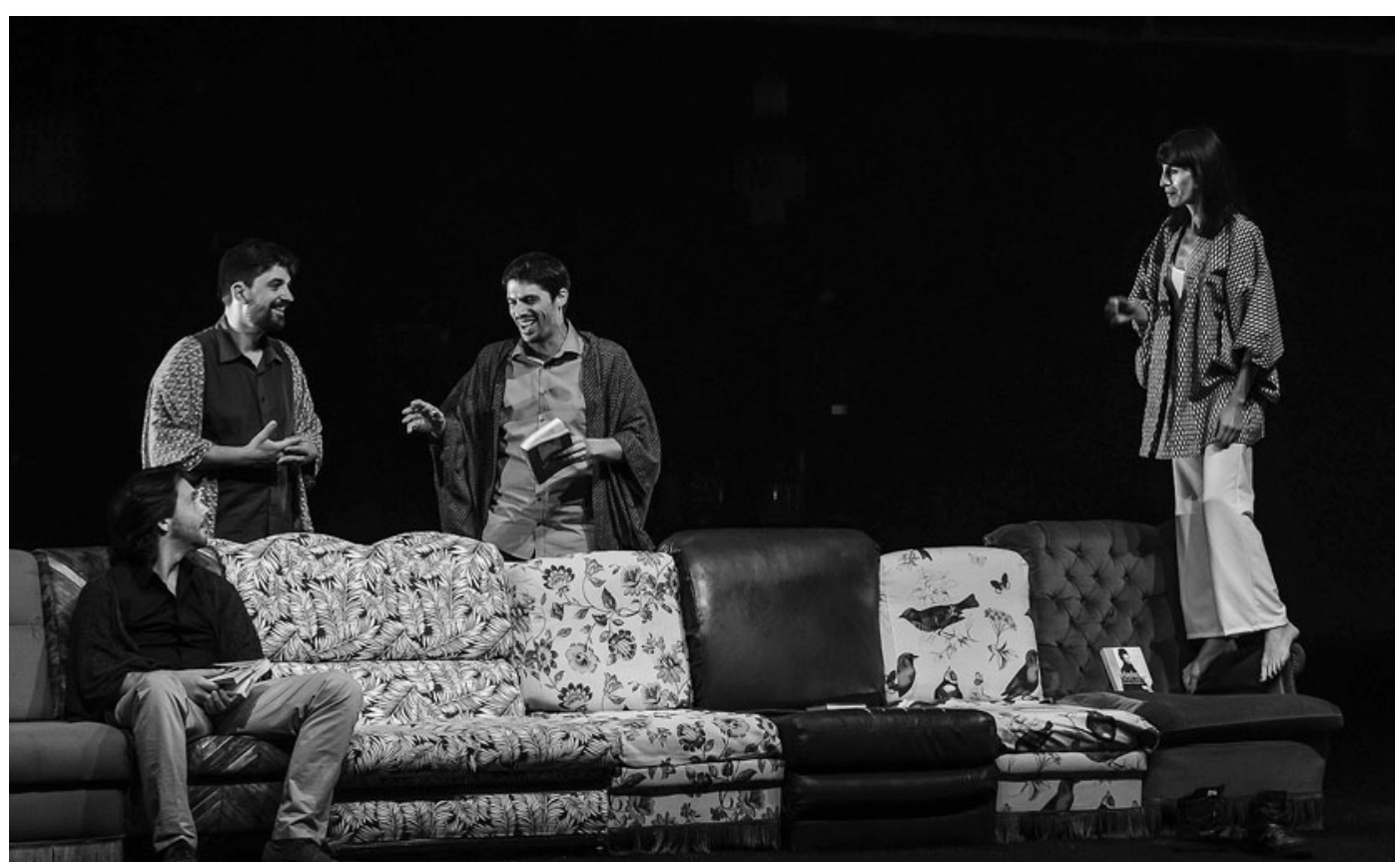

Titulo: Bovary. Autor: Tiago Rodrigues [a partir de Gustave Flaubert]. Encenação: Tiago Rodrigues. Conceito de cenografia e figurinos: Magda Bizarro e Tiago Rodrigues. Construção de cenário:Ângela Rocha. Desenho de Luz: Rui Horta. Música: Alexandre Talhinhas. Direcção de produção e fotografia de cena: Magda Bizarro. Produção executiva: Rita Mendes. Interpretação: Carla Maciel, Gonçalo Waddington, Isabel Abreu, Pedro Gil e Tiago Rodrigues. Produção: Mundo Perfeito, Alkantara Festival, São Luiz Teatro Municipal e Teatro Nacional São João. Local e data de estreia: São Luiz Teatro Municipal, Lisboa, 7 de Junho de 2014.

Cada sorriso escondia um bocejo de tédio, cada alegria uma maldição, todo o prazer a saciedade, e os melhores beijos não deixavam nos lábios senão o irrealizável desejo de uma volúpia mais alta.

Gustave Flaubert (1991: 306)

A Bovary de Tiago Rodrigues, levada à cena no São Luiz Teatro Municipal (SLTM) em Lisboa, no passado mês de Junho, no encerramento do Alkantara Festival, é uma criação artística que ultrapassa a adaptação para teatro do livro Madame Bovary, de Gustave Flaubert, interligando o romance com o processo judicial a que o autor foi sujeito e com algumas cartas que o mesmo escreveu a Louise Colet, sua grande amiga, no decurso do julgamento.

Estes três materiais distintos, inteligentemente manipulados, colocaram em palco, na pele de cinco brilhantes actores, os personagens romanescos designadamente Emma Bovary, Charles Bovary, Rodolphe Boulanger e Léon Dupuis -, o advogado imperial Ernest Pinard, o advogado de defesa Jules Sénard e o próprio Gustave Flaubert. Apesar de os actores representarem diversos papéis, uma mesma personagem ser representada por mais de um actor, os personagens do romance contracenarem com os advogados do julgamento, e o espectáculo decorrer num ritmo acelerado, por vezes vertiginoso, o encadeamento das cenas e o enredo nunca se perde. Esse seria um dos principais riscos deste projecto, no entanto, a inteligibilidade do espectáculo é a evidência da qualidade do texto e do acerto da encenação.

No palco da sala principal do SLTM, cinco actores, um sofá, um cacto, uma caixa de luz e um mapa compõem o "cenário" que, aos poucos, se preenche com dois baús, um pequeno quadro, uma charuteira, uma garrafa de água, um copo, um casaco vermelho, um ramo de flores e,

inevitavelmente, o recipiente com arsénico. Nesta assumida escassez de meios, várias são as histórias que se representam: a do romance, a do julgamento, a da análise tristemente irónica de Flaubert, mas sobretudo a do leitor Tiago Rodrigues, que, com sábio humor, numa aparente desmistificação da grandiosidade intemporal do romance, nos remete subtilmente para os grandes temas da obra, bem como da perseguição judicial que sobre ela recaiu:
Bovary,

de Tiago Rodrigues, enc. Tiago Rodrigues, Mundo Perfeito/Alkantara Festival/SLTM/TNSJ, 2014 (Pedro Gil, Tiago Rodrigues, Gonçalo Waddington e Isabel Abreu), fot. José Frade.
Emilia Costa é licenciada em Direito pela Faculdade de Direito da Universidade de Lisboa e mestre em Estudos de Teatro pela Faculdade de Letras da UL. Adaptou para teatro Timbuktu, de Paul Auster (T. da Trindade) e $O$ jogador de Dostoievski (São Luiz Teatro Municipal). Participou no projecto Curtas (Primeiros

Sintomas) com vários originais seus. 


$$
\begin{array}{r}
<>v \\
\text { Bovary, } \\
\text { de Tiago Rodrigues, } \\
\text { enc. Tiago Rodrigues, } \\
\text { Mundo Perfeito/Alkantara } \\
\text { Festival/SLTM/TNSJ, } 2014 \\
\text { < Isabel Abreu } \\
\text { e Carla Maciel; } \\
>\text { Carla Maciel } \\
\text { e Pedro Gil; } \\
\text { v Carla Maciel, }
\end{array}
$$

Tiago Rodrigues, Gonçalo Waddington e Pedro Gil),

fot. José Frade.
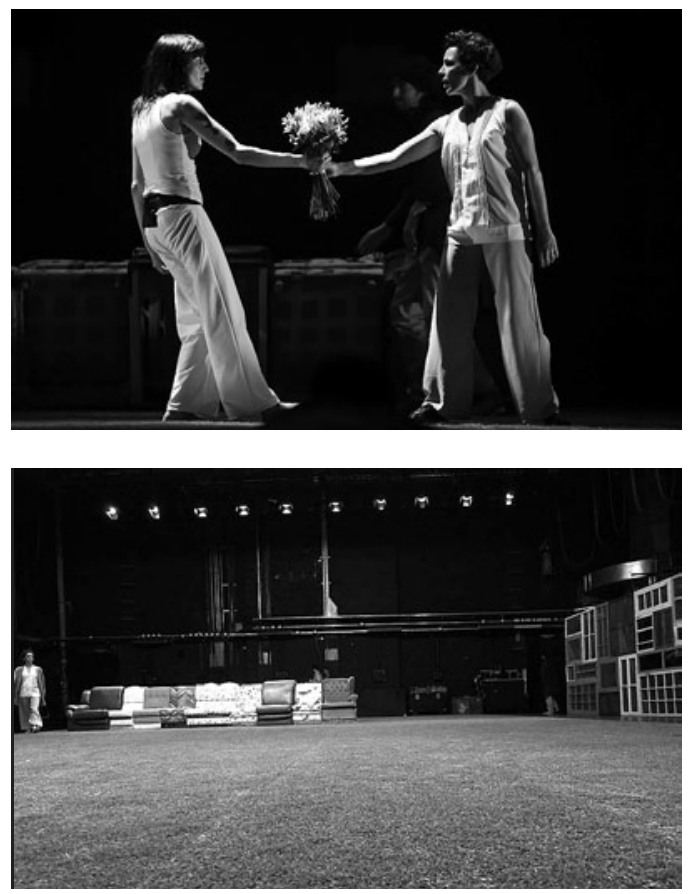

a intangivel busca da felicidade, a vida entediante da mulher burguesa de oitocentos, o prazer feminino, a liberdade artística, a censura estatal e os preconceitos sociais e morais.

Tiago Rodrigues tem essa peculiaridade: em encenações despretensiosas e recheadas de humor lança-nos desafios sobre a profundidade da nossa espécie, a mediocridade social da nossa existência e a nossa inesgotável capacidade de sonhar e criar. Não se trata de mero entretimento, sem objectivo, que muitas vezes o riso permite confundir, menorizar, mas de espectáculos que nos questionam e nos remetem para as questões primordiais da filosofia.

Essa é a razão pela qual, apesar do riso, nos deparamos em Bovary com a sensação incomodativa de vermos como arguido, não Flaubert, mas Emma Bovary, uma personagem que, apesar de nunca ter tido existência real, é encarada como se existisse, dissecando-se os seus pensamentos, os seus desejos e as suas ambições, no intuito de a reconduzir à perversão ou à ingenuidade e, desse modo, a condenar ou absolver. E é neste absurdo que toda a censura artística se traduz, nesta incompreensivel fusão entre a ficção e a realidade, nesta incapacidade em reconhecer que a realidade estará sempre à frente da ficção e que, mesmo que o livro Madame Bovary tivesse sido proibido, continuariam a existir mulheres, nos vários pontos do mundo, por natureza e/ou inteligência, insatisfeitas com o redutor papel que Ihes estava destinado, e a quem apenas uma saida era possivel: o suicidio, quer fosse atingido através da loucura ou do opróbrio.

Também, e apesar do riso, não conseguimos esquecer que o bom leitor de Madame Bovary é precisamente o advogado imperial, aquele que pretende condenar Flaubert - ou mais precisamente Emma Bovary - pela intensidade do seu desejo, pela sua incapacidade de se conformar, pela sua permanente insatisfação. Não é, de facto, o advogado de defesa, que, na obsessão pela absolvição do seu cliente, reduz a profundidade psicológica de Emma à de uma pobre provinciana ingénua e tonta, prestando, assim, um mau serviço ao romance e ao escritor. Uma vez

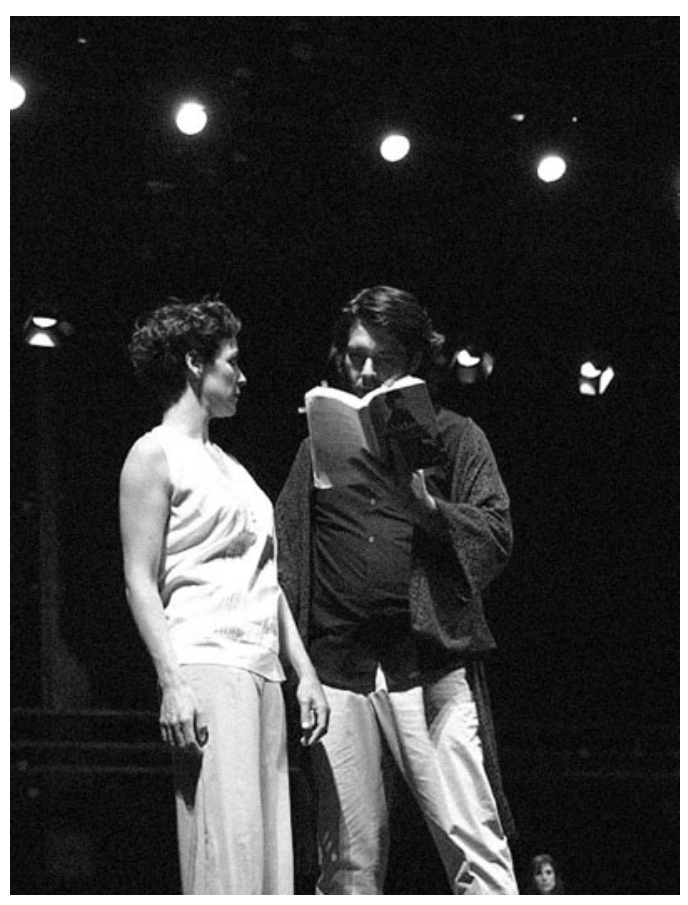

mais, foi preciso negar a obra para que ela pudesse passar pelo crivo da censura.

Ainda apesar do riso, assalta-nos a dor insuportável de Emma, numa representação irrepreensivel de Carla Maciel, traduzida na sua dança frenética, no seu rodopio angustiante e raivoso em busca de ajuda ou na inexpressividade facial com que é beijada. Nesses momentos, por detrás do riso, ergue-se o silêncio, o silêncio claustrofóbico de quem reconhece em si os sonhos desfeitos de Emma.

0 beijo é, aliás, um elemento cénico recorrente neste espectáculo, como símbolo visivel do desejo. É através do desejo carnal que Emma procura a transcendência, por isso, à medida que o espectáculo avança, os personagens deixam-se seduzir pela luxúria e multiplicam-se em beijos, homens com mulheres, homens com homens e mulheres com mulheres, numa ávida tentação orgiástica... Todos, com excepção de Emma, que permanece indiferente ao desejo, aos beijos, ausente, pois, tal como Cassandra, é a única que conhece o futuro. 0 momento mais atordoante desta estranha febre, que tomou conta dos personagens em cena, é a do prolongado e intenso beijo entre os advogados de acusação e defesa. 0 beijo provoca o riso, mas, à medida que se prolonga, e apesar do humor que Ihe está associado, é visivel algum desconforto. 0 adultério feminino já não provoca a agitação moral de outrora, mas um beijo longo, intenso, cheio de volúpia, entre dois homens ainda produz desassossego.

Destaca-se ainda a cena do fiacre, na qual Emma reincide na perdição. 0 sofá tombado é o fiacre $e_{\text {, }}$ escondidos atrás dele, Emma e Léon concretizam as mais escandalosas aventuras amorosas, que, por não serem relatadas, serão tão escabrosas quanto a imaginação de cada leitor/espectador o quiser. Ao mesmo tempo que, ocultados no fiacre/sofá, os amantes atingem o êxtase, o percurso dessa viagem mítica do desejo é narrado velozmente e ampliado pelo microfone em reminiscências circenses, pontuado ainda pelo lamento pungido de Charles chamando Emma. 


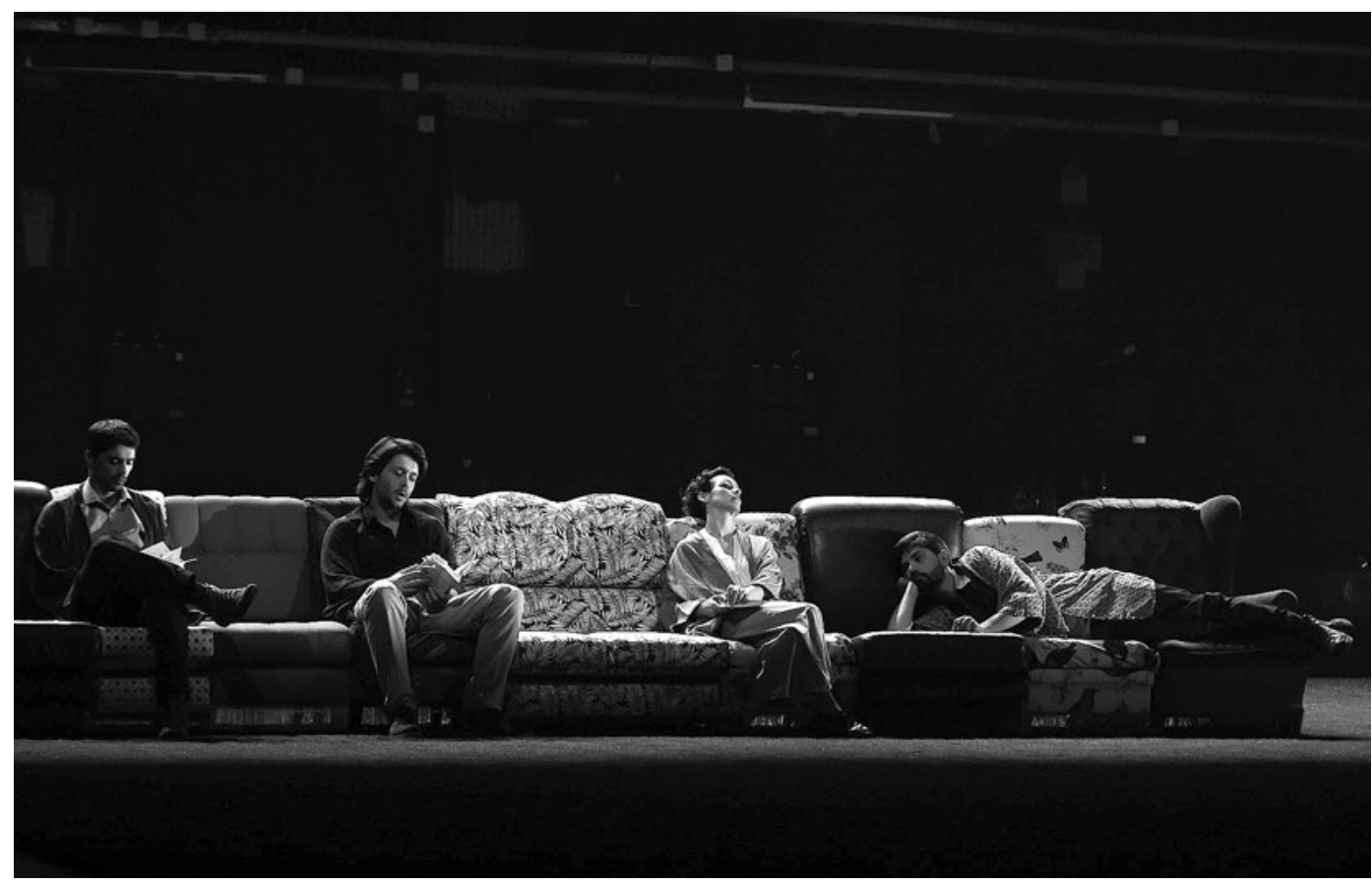

Bovary,

de Tiago Rodrigues, enc. Tiago Rodrigues, Mundo Perfeito/Alkantara Festival/SLTM/TNSJ, 2014 (Gonçalo Waddington Pedro Gil, Carla Maciel e Tiago Rodrigues), fot. José Frade.
Na opção dramatúrgica e cénica de Tiago Rodrigues, os actores estão sempre em palco e assumem-se como actores, vestidos com roupas do dia-a-dia do século XXI, a quem apenas os casacos de mangas largas evocam vagamente as vestes dos tribunais (togas e becas), e que avançam na direcção da luz quando é a sua vez de representar, ora contracenando ora expressamente dirigindo-se ao espectador, fim último de todo o espectáculo, e que aqui funciona numa dupla dimensão: jurado e público. Por vezes, os actores invadem a plateia, reforçando a dimensão do espectáculo como realidade a acontecer, numa construção assumidamente fictícia e, por isso mesmo, mais verdadeira, mais autêntica, mais real. Neste contexto, a caixa de luz é um elemento cénico e cada um dos actores ilumina e escurece a sala, ora revelando numa brancura de hospital o despido cenário de um palco em construção, ora escurecendo nos caminhos da tragédia o destino inevitável dos personagens, dos actores e do público, num deslumbrante desenho de luz de Rui Horta. Também a selecção musical, de Alexandre Talhinhas, intensifica os momentos dramáticos e invoca a tragédia.

Por fim, os actores, estes cinco versáteis actores, que, na sua autenticidade, se apresentam em palco, em cinco personagens principais - Carla Maciel numa desesperançada e hirta Emma Bovary, Pedro Gil num cativante e altivo Ernest Pinard, Gonçalo Waddington num manipulador e divertido Jules Sénard, Isabel Abreu num tristemente irónico Gustave Flaubert e Tiago Rodrigues num tímido e hesitante Charles Bovary -, e em outras tantas personagens secundárias, com excepção de Emma e Charles, sempre e apenas Carla Maciel e Tiago Rodrigues. 0 casal Bovary, o centro do drama, não se multiplica nem desdobra, pois a eles se deve a eternidade. Pelo contrário, os amantes, os advogados de acusação e defesa, o farmacêutico, o escritor, os actores e nós, os espectadores, revelam-se todos mortais, irrelevantes, substituiveis, dispensáveis e mutáveis.

Assistir a esta Bovary é compreender que uma obra- prima da literatura mundial pode ser homenageada de diversos modos e em diversos contextos. É compreender que Emma Bovary pode estar vestida com a roupagem da modernidade e ser ridicularizada pelo advogado imperial, descrevendo-a como uma criatura fútil e mesquinha, mas que a profundidade do seu sofrimento, desse sofrimento ancorado na insatisfação permanente da alma humana, a tornará sempre numa trágica heroína.

Reduzir, ontem como hoje, Emma Bovary a uma tola e insípida burguesa de província, que, cansada do tédio do seu quotidiano, se perdeu na luxúria e no luxo, é não compreender que Emma aspirava aos grandes sentimentos e às grandes emoções. A Emma não interessava coleccionar amantes, como o fazia Rodolphe Boulanger, mas sim atingir a perfeição do Amor e, por isso, ela se entregava aos amantes com uma intensidade que os assustava, dispondo-se a fugir com eles, sem se preocupar com as consequências que tal ousadia traria à sua reputação. Do mesmo modo, não era o acumular de coisas materiais que Ihe interessava, antes sim uma forma de construir o cenário ideal para o Amor, que só deveria conviver com o Belo. Por isso, Emma Bovary era pródiga em ofertas aos seus amantes como prova desse amor, ao invés de procurar premeditadamente enriquecer com eles. Os desaires amorosos de Emma decorrem exactamente da impossibilidade de os seres comuns, com quem se cruza, serem capazes dessa imensidão amorosa e, ironicamente, após a sua morte, apenas o simples e rústico Charles Bovary, que nunca se preocupou com a literatura e que desconhecia a poesia, consegue atingir essa intensa e profunda dimensão amorosa.

Intenso, divertido e provocador, Bovary leva-nos a amar o espectáculo e o livro que o inspirou.

\section{Referências bibliográficas}

FLAUBERT, Gustave (1991), Madame Bovary, trad. João Pedro de Andrade, Lisboa, Relógio d'Água. 